\title{
Incorrect Use of The Web Databases Can Result in Incorrect Information for the Readers: The Case of Lactate-Mitochondria Affair
}

\author{
Salvatore Passarella1* and Avital Schurr ${ }^{2}$ \\ ${ }^{1}$ University Aldo Moro, Italy \\ ${ }^{2}$ Department of Anesthesiology and Perioperative Medicine, University of Louisville School of Medicine, USA
}

Submission: July 17, 2018; Published: August 16, 2018

*Corresponding author: Salvatore Passarella, School of Medicine, University “Aldo Moro” 70100 Bari Piazza Giulio Cesare, Italy, Email: spassarella3@gmail.com

Avital Schurr, Department of Anesthesiology and Perioperative Medicine, University of Louisville School of Medicine Louisville, KY, 40202, USA, Email: avital.schurr@gmail.com

\section{Introduction}

One of the outstanding problems in biochemistry as well as in biological sciences is whether and how each research paper and in particular each review paper reports up-to date information on a specific topic. We suggest to resort to available data bases that sort publications by relevance (i.e. WEB of Sciences and SCOPUS) or by best match (i.e. PubMed). For instance, when searching for "lactate metabolism and cancer mitochondria" on July $9^{\text {th }} 2018$, one finds more than 950 results that includes in the first 6 , three publications from the Passarella Lab showing that cancer mitochondria can take up and metabolize externally added D and L-lactate [1-3]. This finding is further confirmed in the $14^{\text {th }}$ and $15^{\text {th }}$ papers on the list $[4,5]$. Surprisingly, the mitochondrial lactate metabolism in cancer cells is essentially ignored in all listed papers including the one published by the Gladden's lab, which is listed at $43^{\text {th }}$ place [6].

Indeed, Gladden and coworkers are to be commended for their many contributions to understanding lactate metabolism in vivo. This is true also with regard to the paper of Ferguson et al. [6] which provides an important historical record of accomplishments in the field. However, with regard to the authors' interpretations of data on mitochondrial L-lactate transport and metabolism and on the presence of mitochondrial L-lactate deydrogenase (mL-LDH) we offer the following comments. Perhaps, the same comments could be made by any student/researcher after a careful WEB investigation of the topic.

\section{Lactate and Cancer}

To the best of our knowledge, the metabolism of L-lactate was not investigated in cancer cells until 2010-2012. de Bari et al. [3] have shown that externally added L-lactate can enter both normal and cancer prostate cells and their mitochondria, where an mLLDH is located inside mitochondria. In both cell types L-lactate was demonstrated to enter mitochondria in a carrier-mediated manner.
The mL-LDHs proved to differ from the cytosolic enzymes (which themselves differ from one another) and both $\mathrm{mL}-\mathrm{LDH}$ protein level and activity are higher in cancer cells.

A broader investigation of L-lactate transport and metabolism in cancer cell mitochondria was carried out in human hepatocellular carcinoma (Hep G2) cells by Pizzuto et al. [2] in which it was shown i. that Hep G2 cell mitochondria (Hep G2-M) possess an mL$\mathrm{LDH}$, restricted to the inner mitochondrial compartment, which differs from the cytosolic one; ii. that a carrier-mediated L-lactate transport occurs in these mitochondria; iii. that the occurrence of the L-lactate/pyruvate shuttle as well as the appearance outside mitochondria of oxaloacetate, malate and citrate arising from l-lactate uptake and metabolism, all indicating a favoring of an anaplerotic role for L-lactate in Hep G2-M. The existence of monocarboxylate transporter and LDH proteins in mitochondrial reticula of breast cell lines was also shown [7]. The occurrence of L-lactate transport and metabolism in cancer mitochondria was left unmentioned in the corresponding section of the review by Ferguson et al. [6].

Notice also that other aspects of L-lactate and mitochondria interaction were not considered in detail. Thus, in the section of the review entitled 'The brain: part of the cell-to-cell lactate shuttle and site of the astrocyte-neuron lactate shuttle' the paper by Atlante et al. [8] entitled "Transport and metabolism of L-lactate occur in mitochondria from cerebellar granule cells and are modified in cells undergoing low potassium dependent apoptosis" was included in the list of references, but its findings were not considered here. These include i. that externally added L-lactate can enter cerebellar granule cells; ii. that L-lactate enters mitochondria, perhaps via an L-lactate/H+ symporter and is oxidized in a manner stimulated by ADP; iii. that an mL-LDH exists and located in the inner mitochondrial compartment; iv. that externally added L-lactate 
causes reduction of the intramitochondrial pyridine cofactors; v. that an intracellular L-lactate/pyruvate shuttle occurs, the activity of which is limited by the putative L-lactate/pyruvate antiporter; vi. that both L-lactate carriers are different from the pyruvate carrier.

In the section of the review by Ferguson et al. [6] entitled 'Cytosolto-mitochondria lactate shuttle' the authors did not consider either the common definition of a 'shuttle' (according to the Oxford dictionary, 'shuttle' (sometimes) is an intracellular metabolic cycle concerned in the transfer of, e.g., reducing equivalents or carbon chains across membranes and different carriers operate each way across the membrane) or the articles where the reconstruction of the L-lactate/pyruvate shuttle was performed [2,9-11] and in which the investigators' arguments refute the claim that L-LDH is not a mitochondrial enzyme. Moreover, Ferguson et al. [6] consider to be "problematic" an experimental approach (NADH monitoring) used by numerous scientists, including Sir Hans Krebs. That, despite a review by Mayevsky \& Rogatsky [12], which states that "The large numbers of publications by different groups testify to the valuable information gathered in various experimental conditions. The monitoring of NADH levels in the tissue provides the most important information on the metabolic state of the mitochondria in terms of energy production and intracellular oxygen levels." If as a result of L-lactate addition to mitochondria NADH formation is observed, one must conclude that $\mathrm{L}-\mathrm{LDH}$ is present, even if $\mathrm{NAD}(\mathrm{H})$ is a cofactor in a myriad of other biochemical reactions. Moreover, when purified mitochondria are used in the absence of NADH, if L-lactate addition to the mitochondrial suspension results in an increase in the intramitochondrial NAD(P)H fluorescence, which can be inhibited by non-penetrant compounds, one must conclude that L-lactate is able to enter the mitochondria (in a carrier mediated manner) where it is oxidized via an mL-LDH. To the best of our knowledge, a different explanation for this conclusion has not been proposed.

We believe that the possible explanations raised in [6] cannot be supported. For instance, in one case [13], cytochrome c release from mitochondria occurred when $0.2 \mathrm{mM} \mathrm{NADH}$ was added to a cell homogenate containing intact mitochondria. NADH oxidation has been suggested to take place due to an enzyme bound to the plasma membrane. Additionally, none of the mechanisms where cytosolic/ externally added NADH is oxidized can be applied to an experimental situation in which there is no NADH outside mitochondria and where intramitochondrial $\mathrm{NAD}(\mathrm{PH})$ fluorescence is measured. On the other hand, in the experiments where metabolite detecting systems are used and where NADH absorbance is measured, each experiment shows that no/negligible NADH oxidation occurs before L-lactate addition.

It is not surprising that Chen et al. [14] admitted that they were unable to resolve exactly where L-lactate oxidation occurs in mitochondria. Their experimental procedure fails in studying the kinetics of L-lactate transport and metabolism. Nevertheless, their contribution confirms the conclusions already reported in Pizzuto et al (2012) (see above).

Last, in the section of [6] entitled 'Lactate as a signaling molecule' a paper that describes that $\mathrm{H} 2 \mathrm{O} 2$, a signaling molecule, is produced due to L-lactate addition to mitochondria, independently of the respiratory chain [15], was not cited. This is due to a putative flavine-dependent L-lactate oxidase that is restricted to the intermembrane space. Obviously, the possibility that the L-lactate oxidase is, actually, the mL-LDH proposed to reside in the intermembrane space as a part of the lactate oxidation complex was not considered either.

The above listed points are aimed to emphasize the importance of using the available data bases in assuring the inclusion of key publications in all research and review papers submitted for publication in any given research field. It is first and foremost the responsibility of the authors of the paper, although reviewers have their responsibility, too, in assuring that the authors do their due diligence searching the available data bases. We have chosen to use Ferguson et al. most recent review, published in a high impact journal, to illustrate our concern for the ease by which some of the most important findings in our field of research have been ignored.

\section{References}

1. de Bari L, Moro, L. Passarella S (2013) Prostate cancer cells metabolize D-lactate inside mitochondria via a D- lactate dehydrogenase which is more active and highly expressed than in normal cells. FEBS Lett 587(5): 467-473.

2. Pizzuto R, Paventi G, Porcile C, Sarnataro D, Daniele A, et al. (2012) L-Lactate metabolism in HEP G2 cell mitochondria due to the L-lactate dehydrogenase determines the occurrence of the lactate/pyruvate shuttle and the appearance of oxaloacetate, malate and citrate outside mitochondria. Biochim Biophys Acta 1817(9): 1679-1690.

3. de Bari L, Chieppa G, Marra E, Passarella S (2010) L-lactate metabolism can occur in normal and cancer prostate cells via the novel mitochondrial L-lactate dehydrogenase. Int J Oncol 37(6): 1607-1620.

4. de Bari L, Atlante A (2018) Including the mitochondrial metabolism of L-lactate in cancer metabolic reprogramming. Cell Mol Life Sci 75(15): 2763-2776.

5. Passarella S, Schurr A (2018) l-Lactate Transport and Metabolism in Mitochondria of Hep G2 Cells-The Cori Cycle Revisited. Front Oncol 8:120.

6. Ferguson BS, Rogatzki MJ, Goodwin ML, Kane DA, Rightmire Z, et al. (2018) Lactate metabolism: historical context, prior misinterpretations, and current understanding. Eur J Appl Physiol 118(4): 691-728.

7. Hussien R, Brooks GA (2001) Mitochondrial and plasma membrane lactate transporter and lactate dehydrogenase isoform expression in breast cancer cell lines. Physiol Genomics 43(5): 255-264.

8. Atlante A, de Bari L, Bobba A, Marra E, Passarella S (2007) Transport and metabolism of L-lactate occur in mitochondria from cerebellar granule cells and are modified in cells undergoing low potassium dependent apoptosis. Biochim Biophys Acta 1767(11): 1285-1299.

9. Valenti D, de Bari L, Atlante A, Passarella S (2002) L-Lactate transport into rat heart mitochondria and reconstruction of the L-lactate/ pyruvate shuttle. Biochem J 364(Pt 1): 101-104.

10. Passarella S, de Bari L, Valenti D, Pizzuto R, Paventi G, et al. (2008) Mitochondria and L-lactate metabolism. FEBS Lett 582(25-26): 35693576.

11. Passarella S, Paventi G, Pizzuto R (2014) The mitochondrial L-lactate dehydrogenase affair. Front Neurosci 8: 407.

12. Mayevsky A, Rogatsky GG (2007) Mitochondrial function in vivo evaluated by NADH fluorescence: from animal models to human studies. Am J Physiol Cell Physiol 292(2): C615-40.

13. Atlante A, Gagliardi S, Marra E, Calissano P, Passarella S (1999) Glutamate neurotoxicity in rat cerebellar granule cells involves 
cytochrome c release from mitochondria and mitochondrial shuttle impairment. J Neurochem 73(1): 237-246.

14. Chen YJ, Mahieu NG, Huang X, Singh M, Crawford PA, et al. (2016) Lactate metabolism is associated with mammalian mitochondria. Nat Chem Biol 12(11): 937-943.

This work is licensed under Creative Commons Attribution 4.0 License

DOI: 10.19080/JTMP.2018.03.555612
15. de Bari L, Valenti D, Atlante A, Passarella S (2010) L-lactate generates hydrogen peroxide in purified rat liver mitochondria due to the putative L-lactate oxidase localized in the intermembrane space. FEBS Lett 584(11): 2285-2290.

\section{Your next submission with Juniper Publishers} will reach you the below assets

- Quality Editorial service

- Swift Peer Review

- Reprints availability

- E-prints Service

- Manuscript Podcast for convenient understanding

- Global attainment for your research

- Manuscript accessibility in different formats

( Pdf, E-pub, Full Text, Audio)

- Unceasing customer service

Track the below URL for one-step submission https://juniperpublishers.com/online-submission.php 